Research Paper: Immunology

\title{
Meta-analysis of the actions of antithymocyte globulin in patients undergoing allogeneic hematopoietic cell transplantation
}

\author{
Jiaojiao Yuan ${ }^{1,2}$, Renzhi Pei ${ }^{2}$, Wensi Su${ }^{1}$, Junjie Cao ${ }^{2}$ and Ying Lu \\ 1 Medical School of Ningbo University, Ningbo, Zhejiang, P.R. China \\ ${ }^{2}$ Department of Hematology, Yinzhou Hospital Affiliated to Medical School of Ningbo University, Ningbo, Zhejiang, P.R. China \\ Correspondence to: Ying Lu, email: yuhanyang_01@aliyun.com \\ Keywords: antithymocyte globulin, graft-versus-host disease, allogeneic hematopoietic cell transplantation, meta-analysis, Immu- \\ nology and Microbiology Section, Immune response, Immunity \\ Received: August 29, 2016 \\ Accepted: December 20, 2016 \\ Published: January 18, 2017
}

\section{ABSTRACT}

Graft-versus-host disease (GVHD) is a serious complication associated with allogeneic hematopoietic cell transplantation (allo-HCT). Antithymocyte globulin (ATG) is widely used prior to allo-HCT for GVHD prevention, though evidence of its efficacy remains unclear. We therefore identified nine randomized controlled trials (RCTs), enrolling 1089 patients (554 in the ATG group and 535 in the non-ATG group) to conduct a meta-analysis of the actions of ATG in allo-HCT. A relative risk or risk ratio (RR) and $95 \%$ confidence interval (CI) were calculated for each outcome. Rabbit ATG reduced overall acute (a) GVHD (RR 0.77, 95\% CI 0.67-0.89, $P=0.0004$ ), grade III-IV aGVHD (RR 0.53, 95\% CI 0.32-0.88, $P=0.01$ ), overall chronic (c) GVHD (RR $0.52,95 \%$ CI $0.42-0.64, P<0.00001$ ) and extensive CGVHD (RR $0.28,95 \%$ CI $0.18-$ $0.43, P<0.00001$ ), without increased risk of relapse (RR 1.17, 95\% CI 0.91-1.49, $P=0.23$ ). By contrast, horse ATG did not reduce overall aGVHD (RR $1.25,95 \%$ CI $0.88-1.79, P=0.22$ ) or CGVHD (RR 1.67, 95\% CI 0.96-2.91, $P=0.07$ ). ATG marginally reduced 100-day transplant related mortality (RR 0.75, 95\% CI 0.56-1.00, $P=0.05$ ) without compromising overall survival or increased risk of infections. Further studies are required to evaluate the optimal dosage and formulation of ATG in different conditioning regimens of transplantation with varied sources of graft and donor.

\section{INTRODUCTION}

Rapid advances in allo-HCT, especially the development of haploidentical transplantation, have increased the possibility of successful treatment in patients with hematological malignancies [16]. However, $40 \%$ to $90 \%$ of recipients experience increased morbidity, mortality and decreased quality of life due to clinically significant graft-versus-host disease (GVHD), despite substantial progress in the immunobiology of hematopoietic cell allografts [7-12]. The immunosuppressive agent antithymocyte globulin (ATG) has a relatively long half-life and suppresses or kills $T$ cells infused with the graft $[13,14]$. It has been used since the 1970s to prevent severe acute and chronic GVHD (aGVHD and cGVHD, respectively) following allogeneic hematopoietic cell transplantation (alloHCT). Several multicenter, prospective, randomized or nonrandomized studies evaluated the efficacy of ATG against GVHD [15-18]. Nevertheless, their conclusions are conflicting. A previous meta-analysis of ATG for posttransplant GVHD prophylaxis suggested that ATG use for GVHD prevention was not generally recommended, and highlighted the need for further evaluation of the impact of ATG in allo-HCT [19]. Furthermore, the risk of relapse and infections, as well as early transplant related mortality (TRM) and overall survival (OS) following the use of ATG remain unclear $[20,21]$. Accordingly, we updated the randomized controlled trials (RCTs) and performed a meta-analysis to evaluate the potential benefit and risk of ATG use in allo-HCT.

\section{RESULTS}

Selection and characteristics of included studies

As illustrated in Figure 1, an online search of the PubMed and Cochrane Library databases was performed 
to identify and select relevant studies. We initially searched 824 studies, from which 20 were retrieved for detailed evaluation: eleven studies were eventually excluded for reasons explained in Figure 1, and nine RCTs meeting the inclusion criteria were included in the final analysis. These nine studies were published between April 1979 and January 2016, and included a total of 1089 patients: 554 in the ATG group and 535 in the control group. Patients were diagnosed with malignant hematopoietic disorders or aplastic anemia (AA). Nearly all (95\%) of the patients were age 16 years or older. Six trials used rabbit ATG, either thymoglobulin (Genzyme, Cambridge, MA, USA) or ATG-Fresenius (Fresenius, Gräfelfing, Germany), and 3 trials used horse ATG. A single study used peripheral blood stem cells, five studies used bone marrow, and others used both peripheral blood stem cells and bone marrow. The median follow-up ranged from 6 to 72 months. Baseline data on the included studies are summarized in Table 1.

\section{Methodological quality of RCTs}

The risk bias in the included nine RCTs is shown in Figure 2. Generation of a randomization sequence, allocation concealment, and incomplete outcome data were adequately described in 78\% (7/9) of RCTs. Information for the assessment of blinding was insufficient: only $33 \%$ (3/9) of RCTs were open-label studies, and none of the remaining 6 trials were described as double-blind or blinded. All of the studies described withdrawals and drop-outs. The overall risk of bias was moderate in the nine studies selected for analysis.

\section{GVHD}

\section{aGVHD (overall aGVHD and grade III-IV aGVHD)}

As illustrated in Figure 3, five studies that included 680 patients were analyzed for overall aGVHD. Among the included trials, moderate heterogeneity $\left(\chi^{2}=6.46\right.$, $\left.d f=4(P=0.17) ; I^{2}=38 \%\right)$ was observed. Fortunately, in subgroup analysis, no heterogeneity $\left(I^{2}=0 \%\right)$ was found in either the rabbit or horse subgroups. Rabbit ATG effectively reduced the incidence of overall aGVHD $(\mathrm{RR}=0.77,95 \% \mathrm{CI}=0.67-0.89, P=0.0004)$, whereas horse ATG was not associated with significant reduction in overall aGVHD $(\mathrm{RR}=1.25,95 \% \mathrm{CI}=0.88-1.79, P=$ 0.22). Six RCTs that included 831 patients treated only with rabbit ATG reported grade III-IV aGVHD data. The pooled results showed a statistically significant reduction in the rabbit ATG arm compared with the control arm $(\mathrm{RR}=0.53,95 \% \mathrm{CI}=0.32-0.88, P=0.01)$. However, moderate heterogeneity $\left(\chi^{2}=10.30, d f=5(P=0.07) ; I^{2}=\right.$ $51 \%$ ) was present among the included trials.

\section{cGVHD (overall cGVHD and extensive cGVHD)}

Eight RCTs with 777 patients were evaluated for the incidence of overall cGVHD. Statistically significant heterogeneity $\left(\chi^{2}=17.95, d f=7(P=0.01) ; I^{2}=61 \%\right)$ was observed within the pooled result. Based on subgroup analysis, rabbit ATG effectively reduced the incidence of overall cGVHD $(\mathrm{RR}=0.52,95 \% \mathrm{CI}=0.42-0.64, P<$ $0.00001)$. On the other hand, no statistical difference (RR $=1.67,95 \% \mathrm{CI}=0.96-2.91, P=0.07)$ in the incidence of overall cGVHD was found in the group administered horse ATG compared with the control group. And there was no heterogeneity $\left(I^{2}=0 \%\right)$ among included studies in either the rabbit or horse subgroup. Three trials comprising 439 patients used only rabbit ATG to evaluate extensive cGVHD. The pooled results showed a significant reduction in the rabbit ATG group compared with the non-ATG group $(\mathrm{RR}=0.28,95 \% \mathrm{CI}=0.18-0.43, P<0.00001)$, with no heterogeneity $\left(I^{2}=0 \%\right)$ among the included RCTs.

\section{Relapse and infections}

Six studies with a total of 831 patients all used rabbit ATG to analyze the incidence of relapse between the ATG and non-ATG arms. No heterogeneity $\left(I^{2}=0 \%\right)$ was observed among the included RCTs. The rate of relapse was similar in the rabbit ATG and non-ATG groups (RR $=1.17,95 \% \mathrm{CI}=0.91-1.49, P=0.23)$. Data on infections were obtained from 4 trials, with 535 enrolled patients. The pooled outcomes showed rabbit and horse ATG did not affect the incidence of infections $(\mathrm{RR}=1.05,95 \% \mathrm{CI}$ $=0.82-1.33, P=0.71)$. And moderate heterogeneity $\left(\chi^{2}=\right.$ $\left.6.41, d f=3(P=0.09) ; I^{2}=53 \%\right)$ was present among the included studies.

\section{0-day TRM and OS (1-year OS and 2-year OS)}

Data pertaining to 100-day TRM were extracted from $78 \%$ (7/9) of the RCTs, enrolling 738 patients. A marginally significant benefit for 100-day TRM was observed in the group treated with rabbit or horse ATG for GVHD prophylaxis $(\mathrm{RR}=0.75,95 \% \mathrm{CI}=0.56-1.00$, $P=0.05)$. There was no heterogeneity $\left(I^{2}=0 \%\right)$ among the studies. One-year OS data were extracted from all of the nine RCTs, enrolling a total of 1089 patients. And data on 2-year OS were reported by six RCTs, enrolling 765 patients. No heterogeneity $\left(I^{2}=0 \%\right)$ was observed among included studies for either 1 -year or 2-year OS. The pooled hazard ratio for the comparison of the ATG arm versus non-ATG arm was $\mathrm{RR}=1.06,95 \% \mathrm{CI}=0.97-1.15$, $P=0.18$ for $\mathrm{OS}$ at 1 year and $\mathrm{RR}=1.03,95 \% \mathrm{CI}=0.93-$ $1.15, P=0.55$ for OS at 2 years. Thus pooled outcomes showed a statistically insignificant benefit for 1-year OS and 2-year OS with the use of rabbit or horse ATG in patients receiving allo-HCT. 
Table 1: Characteristics of included RCTs

\begin{tabular}{|c|c|c|c|c|c|c|c|c|c|c|c|c|c|}
\hline Auther & Year & $\begin{array}{l}\text { ATG/ } \\
\text { Non-ATG }\end{array}$ & Gisease & Age & $\begin{array}{l}\text { Male sex } \\
\text { no. (\%) }\end{array}$ & $\begin{array}{l}\text { Disease status at } \\
\text { transplant } \\
\text { no. }(\%)\end{array}$ & Conditioning & $\begin{array}{l}\text { Type of } \\
\text { ATG }\end{array}$ & Dose of ATG & $\begin{array}{l}\text { Graft } \\
\text { source }\end{array}$ & Donor & $\begin{array}{l}\text { Enrollment } \\
\text { Period }\end{array}$ & $\begin{array}{l}\text { Median follow- } \\
\text { up Mo (range) }\end{array}$ \\
\hline $\begin{array}{l}\text { Weiden, PL } \\
{[26]}\end{array}$ & 1979 & 29/27 & $\mathrm{AL}+\mathrm{CML}+\mathrm{LLL}$ & $\begin{array}{l}17(1-32)(\mathrm{A}) \\
19(2-47)(\mathrm{N})\end{array}$ & $\begin{array}{l}16(55)(\mathrm{A}) \\
19(70)(\mathrm{N})\end{array}$ & $\begin{array}{l}\text { CR 13(45)(A), 13(48)(N) } \\
\text { Relapse 16(55) (A), 14(52) (N) }\end{array}$ & Cy $120 \mathrm{mg} \mathrm{kg}+10$ Gy TBI & Horse ATG & 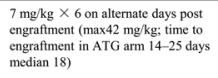 & BM & MRD & $1976.6-1978.1$ & $6 \sim 16$ \\
\hline $\begin{array}{l}\text { Doney, KC } \\
{[27]}\end{array}$ & 1981 & $30 / 42$ & $\mathrm{AL}+\mathrm{CML}+\mathrm{LLL}$ & $19(2-53)$ & NR & NR & Cyl20 mg $\mathrm{kg}+10-15$ Gy TBI & Horse ATG & $\begin{array}{l}20 \mathrm{mg} / \mathrm{kg} \times 6 \text { alternate days from } \\
\text { day }+7 \text { post transplant }\end{array}$ & BM & MRD & 1978.4-1979.6 & $>12$ \\
\hline $\begin{array}{l}\text { Bacigalupo, A } \\
{[15]}\end{array}$ & 2001a & $29 / 25$ & $\begin{array}{l}\text { hematologic } \\
\text { malignancies }\end{array}$ & $\begin{array}{l}28(18-48)(\mathrm{A}) \\
29(13-51)(\mathrm{N})\end{array}$ & NR & CRI/CP 18(62)(A), 15(60)(N) & Cyl20 mg $/ \mathrm{kg}+10-12$ Gy TBI & Rabbit ATG & $3.75 \mathrm{mg} / \mathrm{kg}$ on days $-4,-3$ & BM & MUD & $1995.12-1997.12$ & $\begin{array}{l}28.5(\mathrm{~A}) \\
34.7 \mathrm{~N})\end{array}$ \\
\hline $\begin{array}{l}\text { Bacigalupo, A } \\
{[15]}\end{array}$ & $2001 \mathrm{~b}$ & $27 / 28$ & $\begin{array}{l}\text { hematologic } \\
\text { malignancies }\end{array}$ & $\begin{array}{l}32(14-52)(\mathrm{A}) \\
28(14-46)(\mathrm{N})\end{array}$ & $\mathrm{NR}$ & $\mathrm{CRI} / \mathrm{CP} 6(22)(\mathrm{A}), 10(36)(\mathrm{N})$ & Cyl20 mg $\mathrm{kg}+10-12 \mathrm{~Gy} \mathrm{TBI}$ & Rabbit ATG & $3.75 \mathrm{mg} / \mathrm{kg}$ on days $-5,-4,-3,-2$ & BM & MUD & 1997.12-2000.7 & $\begin{array}{c}17.7(\mathrm{~A}) \\
18(\mathrm{~N})\end{array}$ \\
\hline $\begin{array}{l}\text { Champlin, E } \\
{[28]}\end{array}$ & 2007 & $70 / 60$ & SAA & $\begin{array}{l}23(1-51)(\mathrm{A}) \\
26(4-51)(\mathrm{N})\end{array}$ & $\begin{array}{l}46(66)(\mathrm{A}) \\
35(58)(\mathrm{N})\end{array}$ & NR & Cy200 mg/kg & Horse ATG & $30 \mathrm{mg} / \mathrm{kg}$ on days -5 to -3 & $98 \% \mathrm{BM}$ & MRD & $1994-2001$ & 72 \\
\hline $\begin{array}{l}\text { Finke, J } \\
{[29]}\end{array}$ & 2009 & 103/98 & $\mathrm{AL}+\mathrm{CML}+\mathrm{MDS}$ & $\begin{array}{l}40(18-60)(\mathrm{A}) \\
39(18-60)(\mathrm{N})\end{array}$ & $\begin{array}{l}58(56)(\mathrm{A}) \\
58(59)(\mathrm{N})\end{array}$ & $\begin{array}{l}\text { Early } 64(62)(\mathrm{A}), 43(43.8)(\mathrm{N}) \\
\text { Advanced } 39(38)(\mathrm{A}), 55(56)(\mathrm{N})\end{array}$ & $\begin{array}{l}\mathrm{Bu} C \mathrm{Cy} 120 \mathrm{mg} / \mathrm{kg} \text { or } \\
\mathrm{Cy} 120 \mathrm{mg} \mathrm{kg}+\mathrm{TBI} 8-12 \mathrm{~Gy}\end{array}$ & Rabbit ATG & $20 \mathrm{mg} / \mathrm{kg}$ on days $-3,-2,-1$ & $\begin{array}{l}\text { BM or } \\
\text { PBSC }\end{array}$ & MUD & $2003.5-2007.2$ & 48 \\
\hline $\begin{array}{l}\text { Bacigalupo, A } \\
{[30]}\end{array}$ & 2010 & $84 / 86$ & $\mathrm{AL}+\mathrm{CML}+$ other & $\begin{array}{l}54 \%>35 \text { (A) } \\
55 \%>35(\mathrm{~N})\end{array}$ & $\begin{array}{l}\text { Female donor } \\
\text { male recipient } \\
10(\mathrm{~A}), 17(\mathrm{~N})\end{array}$ & $\begin{array}{l}\text { Early } 44(52)(\mathrm{A}), 45(52)(\mathrm{N}) \\
\text { Advanced } 40(48)(\mathrm{A}), 41(48)(\mathrm{N})\end{array}$ & $\begin{array}{l}\text { Cy } 120 \mathrm{mg} / \mathrm{kg}+12 \mathrm{~Gy} \text { TBI } \\
\text { Cyl00 m/kg t thiotepa } 10 \mathrm{mg} / \mathrm{kg}\end{array}$ & Rabbit ATG & $3.75 \mathrm{mg} / \mathrm{kg}$ on days $-3,-2$ & $\begin{array}{l}\text { BM or } \\
\text { PBSC }\end{array}$ & $\begin{array}{l}55 \% \mathrm{MMUD} \\
15 \% \mathrm{MMRD} \\
30 \% \mathrm{MUD}\end{array}$ & NR & $\begin{array}{l}43.3(\mathrm{~A}) \\
48(\mathrm{~N})\end{array}$ \\
\hline $\begin{array}{l}\text { Kroger, } N \\
{[16]}\end{array}$ & 2016 & $83 / 72$ & AL & $\begin{array}{l}39(18-64)(\mathrm{A}) \\
43.5(21-61)(\mathrm{N})\end{array}$ & $\begin{array}{l}53(63.9)(\mathrm{A}) \\
40(55.6)(\mathrm{N})\end{array}$ & $\begin{array}{l}\text { CR1 73(88)(A), 66(91.7)(N) } \\
\text { CR2 10(12)(N), 6(8.3)(N) }\end{array}$ & 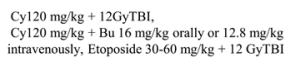 & Rabbit ATG & $10 \mathrm{mg} / \mathrm{kg}$ on days $-3,-2,-1$ & PBSC & MRD & $2006.12-2012.2$ & 24 \\
\hline $\begin{array}{l}\text { Walker, I } \\
{[17]}\end{array}$ & 2016 & 99:97 & $\begin{array}{l}\text { AL+CL+MDS } \\
\text { +Lymphoma } \\
\text { +other }\end{array}$ & $\begin{array}{l}49(40-57)(\mathrm{A}) \\
49(40-56)(\mathrm{N})\end{array}$ & $\begin{array}{l}63(64)(\mathrm{A}) \\
65(67)(\mathrm{N})\end{array}$ & $\begin{array}{l}\text { Early } 57(58)(\mathrm{A}), 59(61)(\mathrm{N}) \\
\text { Late } 34(34)(\mathrm{A}), 34(35)(\mathrm{N}) \\
\text { Other } 8(8)(\mathrm{A}), 4(4)(\mathrm{N})\end{array}$ & Myeloablative or RIC conditioning & Rabbit ATG & $\begin{array}{l}0.5 \mathrm{mg} / \mathrm{kg} \text { on day }-2,2.0 \mathrm{mg} / \mathrm{kg} \\
\text { on day }-1,2.0 \mathrm{mg} / \mathrm{kg} \text { on day }+1\end{array}$ & $\begin{array}{l}\text { BM or } \\
\text { PBSC }\end{array}$ & $\begin{array}{l}83 \% \text { MUD } \\
17 \% \text { MMUD }\end{array}$ & $2010.6-2013.8$ & 12 \\
\hline
\end{tabular}

NR: Not reported; AL: Acute leukemia; CL: Chronic leukemia; CML: Chronic myeloid leukemia; LLL: Lymphoblastic lymphoma with leukemia; SAA: Severe aplastic anemia; MDS: Myelodysplastic syndrome; BM: bone marrow; PBSC: peripheral blood stem cell; MRD: matched related donor; MUD: matched unrelated donor; MMUD: mismatched unrelated donor; MMRD: mismatched related donor.

\section{DISCUSSION}

GVHD is one of the most severe complications following allo-HCT [31-35]. Clinically significant GVHD (grade III-IV aGVHD and extensive cGVHD) may lead to morbidity, mortality, and poor quality of life.
Unfortunately, GVHD prophylaxis with small molecule immunosuppressive drugs or pure ex vivo, but not in vivo, $\mathrm{T}$ cell depletion may increase the rate of relapse and infections [36-40]. Accordingly, there is an urgent need to look for a more effective therapy. ATG has been used for GVHD prophylaxis since the 1970s. However, the efficacy

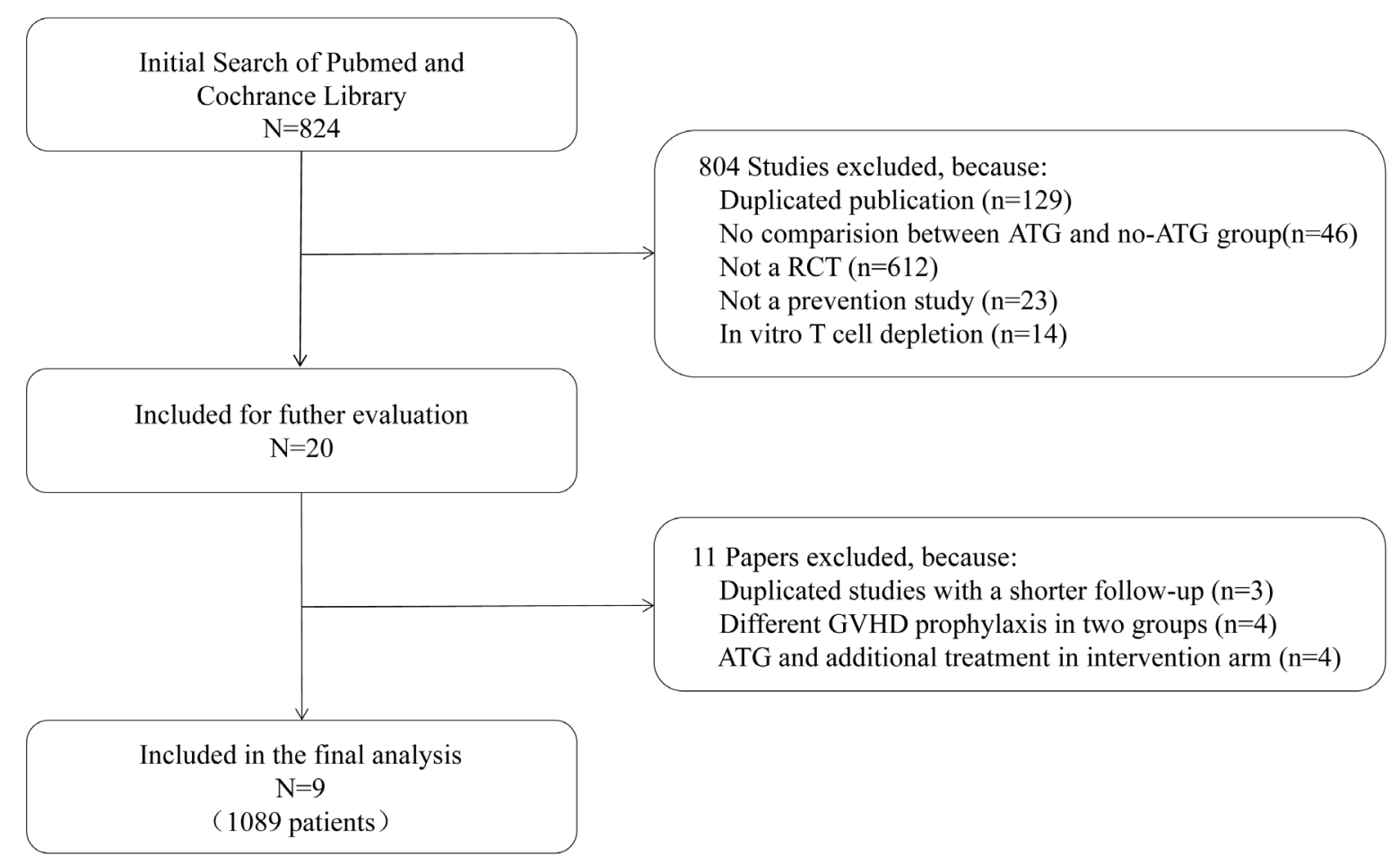

Figure 1: Flowchart outlining the search strategy and data selection. 
and risk of ATG use for prevention of GVHD are not consistent across several RCTs. We therefore conducted a meta-analysis of nine RCTs to critically evaluate the available evidence regarding the role of ATG in allo-HCT.

The final outcomes of this meta-analysis fully validated the efficacy of rabbit ATG for reducing aGVHD (overall aGVHD and grade III-IV aGVHD) and cGVHD (overall cGVHD and extensive cGVHD). By contrast, horse ATG was not associated with overall aGVHD and overall cGVHD. Unfortunately, data related to the comparative efficacy of different ATG formulations in allo$\mathrm{HCT}$ are unavailable. Rabbit ATG is more efficacious than horse ATG for GVHD prevention, overall. Nonetheless, horse ATG appears more efficacious for GVHD prophylaxis in patients with aplastic anemia. Further research is required to explore the optimal treatment formulations. In addition, the immunosuppressive effect of ATG is multifactorial and not sufficiently elucidated. ATG can persist in HCT recipients for weeks to months, suppressing or killing $\mathrm{T}$ cells infused with the graft for a relatively long term. This is thought to be the primary mechanism by which ATG reduces GVHD [13, 14, 41-43].

It is controversial whether use of ATG increases the risk of infections and relapse after allo-HCT. Some studies suggest the potent immunosuppression achieved with ATG may delay immune recovery and thus increase the risk of infections and relapse [20, 44-47]. However, others suggest ATG only increases the risk of infections or relapse at a high dose [21, 48, 49, 50-53]. Our metaanalysis found that the rate of infectious complications was
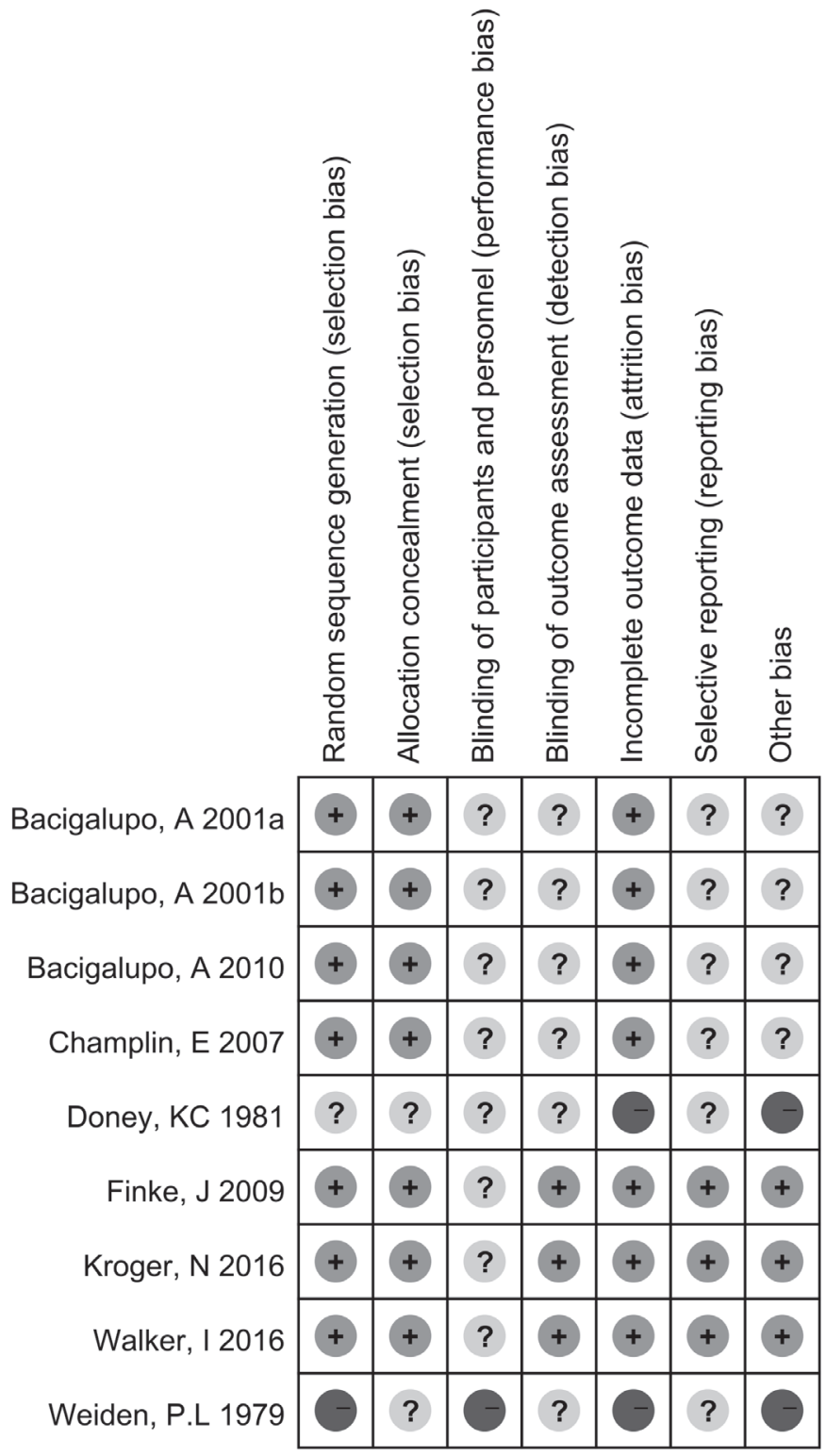

Figure 2: Risk of bias in the nine included RCTs. 
ATG Control Risk Ratio $\quad$ Risk Ratio

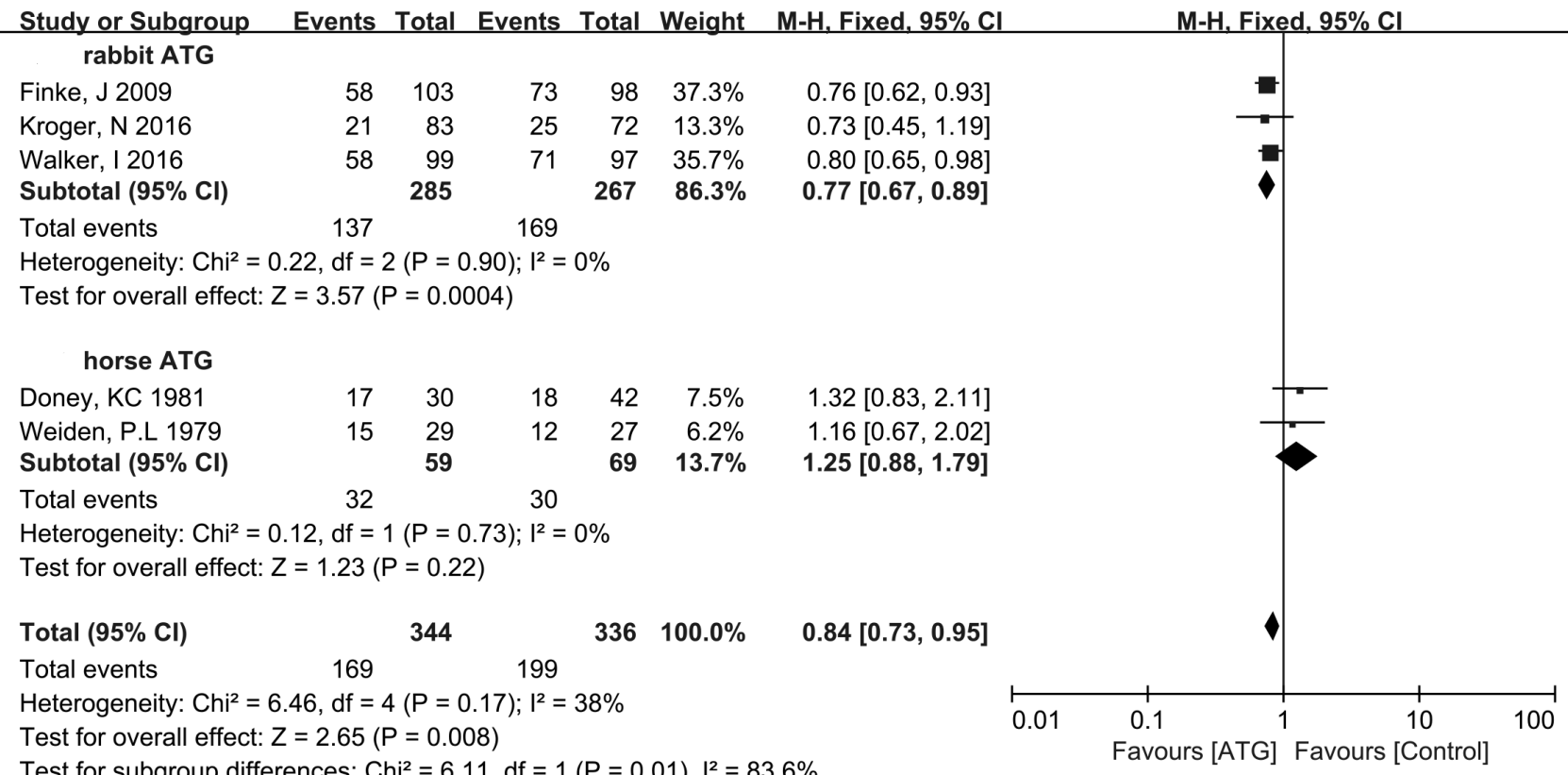

Test for subaroun differences: $\mathrm{Chi}^{2}=6.11 . \mathrm{df}=1(\mathrm{P}=0.01) . \mathrm{I}^{2}=83.6 \%$

$\begin{array}{lllll}\text { Rabbit ATG } & \text { ATG } & \text { Control } & \text { Risk Ratio } & \text { Risk Ratio }\end{array}$

Study or Subgroup Events Total Events Total Weight M-H, Random, 95\% Cl

$\begin{array}{lllllll}\text { Bacigalupo, A 2001a } & 12 & 29 & 9 & 25 & 21.1 \% & 1.15[0.58,2.27]\end{array}$

$\begin{array}{lllllll}\text { Bacigalupo, A 2001b } & 3 & 27 & 14 & 28 & 12.5 \% & 0.22[0.07,0.69]\end{array}$

$\begin{array}{lllllll}\text { Bacigalupo, A } 2010 & 4 & 84 & 13 & 86 & 13.2 \% & 0.32[0.11,0.93]\end{array}$

$\begin{array}{llllll}\text { Finke, J } 2009 & 12 & 103 & 24 & 98 & 22.2 \%\end{array}$

$\begin{array}{llllll}\text { Kroger, N } 2016 & 2 & 83 & 6 & 72 & 7.8 \%\end{array}$

Walker, I $2016 \quad 16 \quad 99 \quad 20 \quad 97 \quad 23.2 \%$

$0.48[0.25,0.90]$

$0.29[0.06,1.39]$

$0.78[0.43,1.42]$

Total $(95 \% \mathrm{Cl})$

425

Total events

49

$406 \quad 100.0 \%$

$0.53[0.32,0.88]$

Heterogeneity: $\mathrm{Tau}^{2}=0.19 ; \mathrm{Chi}^{2}=10.30, \mathrm{df}=5(\mathrm{P}=0.07) ; \mathrm{I}^{2}=51 \%$

Test for overall effect: $Z=2.47(P=0.01)$

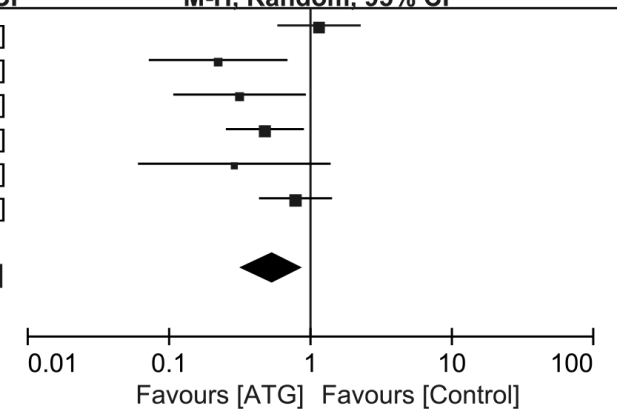

ATG Control Risk Ratio

Study or Subgroup Events Total Events Total Weight M-H. Random, 95\% Cl rabbit ATG

Bacigalupo, A 2001a

Bacigalupo, A 2001b

$\begin{array}{lllll}8 & 22 & 13 & 20 & 13.3 \%\end{array}$

Finke, J 2009

Kroger, N 2016

Walker, I 2016

Subtotal $(95 \% \mathrm{Cl})$

Total events

$\begin{array}{rr}7 & 18 \\ 27 & 90 \\ 22 & 78 \\ 20 & 91 \\ & 299\end{array}$

Heterogeneity: $\mathrm{Tau}^{2}=0.00 ; \mathrm{Chi}^{2}=2.69, \mathrm{df}=4(\mathrm{P}=0.61) ; \mathrm{I}^{2}=0 \%$

Test for overall effect: $Z=6.07(P<0.00001)$

\begin{tabular}{|c|c|c|c|c|c|c|}
\hline \multicolumn{7}{|l|}{ horse ATG } \\
\hline Champlin, E 2007 & 21 & 65 & 11 & 53 & $13.4 \%$ & $1.56[0.83,2.93$ \\
\hline Doney, KC 1981 & 4 & 21 & 3 & 30 & $5.1 \%$ & $1.90[0.47,7.64$ \\
\hline Weiden, P.L 1979 & 4 & 24 & 1 & 16 & $2.5 \%$ & $2.67[0.33,21.7$ \\
\hline Subtotal $(95 \% \mathrm{Cl})$ & & 110 & & 99 & $21.0 \%$ & $1.67[0.96,2.9$ \\
\hline Total events & 29 & & 15 & & & \\
\hline \multicolumn{7}{|c|}{$\begin{array}{l}\text { Heterogeneity: } \mathrm{Tau}^{2}=0.00 ; \mathrm{Chi}^{2}=0.28, \mathrm{df}=2(P=0.87) ; I^{2}=0 \% \\
\text { Test for overall effect: } Z=1.81(P=0.07)\end{array}$} \\
\hline \multicolumn{2}{|l|}{ Total $(95 \% \mathrm{Cl})$} & 409 & & 368 & $100.0 \%$ & $0.69[0.49,0.9$ \\
\hline Total events & 113 & & 159 & & & \\
\hline \multicolumn{7}{|c|}{ Heterogeneity: $\mathrm{Tau}^{2}=0.14 ; \mathrm{Chi}^{2}=17.95, \mathrm{df}=7(\mathrm{P}=0.01) ; \mathrm{I}^{2}=61 \%$} \\
\hline \multicolumn{7}{|c|}{ Test for overall effect: $Z=2.04(P=0.04)$} \\
\hline \multicolumn{7}{|c|}{ Test for subaroun differences: $\mathrm{Chi}^{2}=14.73 \mathrm{df}=1(\mathrm{P}=0.0001) . \mathrm{I}^{2}=93.2 \%$} \\
\hline
\end{tabular}

$\begin{array}{lll}11 & 18 & 12.5 \%\end{array}$

$\begin{array}{lll}47 & 80 & 18.8 \%\end{array}$

$\begin{array}{lll}46 & 68 & 18.3 \%\end{array}$

$27-83-16.1 \%$

$0.56[0.30,1.06]$

$0.64[0.32,1.26]$

$0.51[0.35,0.74]$

$0.42[0.28,0.62]$

$0.68[0.41,1.11]$

$0.52[0.42,0.64]$ 144

$269 \quad 79.0 \%$

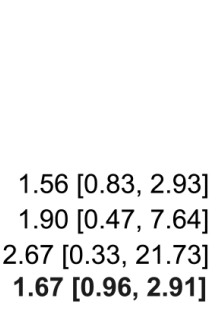




\begin{tabular}{|c|c|c|c|c|c|c|c|c|c|c|}
\hline $\begin{array}{l}\text { Rabbit ATG } \\
\text { Study or Subgroup }\end{array}$ & $\begin{array}{l}\text { ATG } \\
\text { Events }\end{array}$ & Total & $\begin{array}{l}\text { Contr } \\
\text { Events }\end{array}$ & $\begin{array}{l}\text { ol } \\
\text { Total }\end{array}$ & Weight & $\begin{array}{c}\text { Risk Ratio } \\
\text { M-H, Fixed, 95\% } \mathrm{Cl}\end{array}$ & & $\begin{array}{r}\text { Risk } \\
\text { M-H, Fix }\end{array}$ & $\begin{array}{l}\text { Ratio } \\
\text { ed, } 95 \% \mathrm{Cl}\end{array}$ & \\
\hline Bacigalupo, A 2010 & 7 & 64 & 16 & 61 & $21.1 \%$ & $0.42[0.18,0.94]$ & & & & \\
\hline Finke, J 2009 & 11 & 90 & 34 & 80 & $46.3 \%$ & $0.29[0.16,0.53]$ & & & & \\
\hline Kroger, N 2016 & 5 & 76 & 24 & 68 & $32.6 \%$ & $0.19[0.08,0.46]$ & & & & \\
\hline Total $(95 \% \mathrm{Cl})$ & & 230 & & 209 & $100.0 \%$ & $0.28[0.18,0.43]$ & & & & \\
\hline Total events & 23 & & 74 & & & & & & & \\
\hline $\begin{array}{l}\text { Heterogeneity: } \mathrm{Chi}^{2}= \\
\text { Test for overall effect: }\end{array}$ & $\begin{array}{l}69, \mathrm{df}=2 \\
=5.80(\mathrm{P}\end{array}$ & $\begin{array}{l}2(P=0 \\
2<0.0\end{array}$ & $\begin{array}{l}.43) ;\left.\right|^{2}= \\
001)\end{array}$ & & & & 0.01 & $\begin{array}{l}0.1 \\
\text { Favours }[\mathrm{ATG}]\end{array}$ & $1 \frac{10}{\text { Favours [Control] }}$ & 100 \\
\hline $\begin{array}{c}\text { Rabbit ATG } \\
\text { Study or Subgroup }\end{array}$ & $\begin{array}{r}\text { ATG } \\
\text { Events }\end{array}$ & Total & $\begin{array}{l}\text { Contr } \\
\text { Events }\end{array}$ & $\begin{array}{l}\text { ol } \\
\text { Total }\end{array}$ & Weight & $\begin{array}{c}\text { Risk Ratio } \\
\mathrm{M}-\mathrm{H}, \text { Fixed, } 95 \% \mathrm{Cl}\end{array}$ & & $\begin{array}{r}\text { Risk } \\
\text { M-H, Fix }\end{array}$ & $\begin{array}{l}\text { Ratio } \\
\text { ed, } 95 \% \mathrm{Cl}\end{array}$ & \\
\hline Bacigalupo, A 2001a & 3 & 29 & 3 & 25 & $3.7 \%$ & $0.86[0.19,3.90]$ & & & & \\
\hline Bacigalupo, A 2001b & 10 & 27 & 5 & 28 & $5.6 \%$ & $2.07[0.81,5.28]$ & & & & \\
\hline Bacigalupo, A 2010 & 24 & 84 & 21 & 86 & $23.6 \%$ & $1.17[0.71,1.93]$ & & & & \\
\hline Finke, J 2009 & 30 & 103 & 23 & 98 & $26.8 \%$ & $1.24[0.78,1.98]$ & & & & \\
\hline Kroger, N 2016 & 27 & 83 & 18 & 72 & $21.9 \%$ & $1.30[0.78,2.16]$ & & & & \\
\hline Walker, I 2016 & 11 & 99 & 16 & 97 & $18.4 \%$ & $0.67[0.33,1.38]$ & & & . & \\
\hline Total $(95 \% \mathrm{Cl})$ & & 425 & & 406 & $100.0 \%$ & $1.17[0.91,1.49]$ & & & 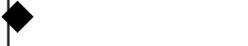 & \\
\hline Total events & 105 & & 86 & & & & & & & \\
\hline \multicolumn{5}{|c|}{$\begin{array}{l}\text { Heterogeneity: } \text { Chi }^{2}=4.13, d f=5(P=0.53) ; I^{2}=0 \% \\
\text { Test for overall effect: } Z=1.21(P=0.23)\end{array}$} & & & 0.01 & $\begin{array}{l}0.1 \\
\text { Favours [ATG] }\end{array}$ & $\begin{array}{lc}1 & 10 \\
\text { | Favours [Control] }\end{array}$ & 100 \\
\hline
\end{tabular}

ATG Control Risk Ratio

Study or Subgroup Events Total Events Total Weight M-H, Random, $95 \% \mathrm{Cl}$ rabbit ATG

Kroger, N 2016

Walker, I 2016

Subtotal $(95 \% \mathrm{Cl})$

$\begin{array}{rrrrr}48 & 83 & 39 & 72 & 29.6 \% \\ 42 & 99 & 37 & 97 & 24.7 \% \\ & 182 & & 169 & 54.3 \% \\ 90 & & 76 & & \end{array}$

$\begin{array}{lcc}\text { Total events } & 90 & 76 \\ \text { Heterogeneity: } \mathrm{Tau}^{2}=0.00 ; \mathrm{Chi}^{2}=0.03, \mathrm{df}=1(\mathrm{P}=0.85) ; \mathrm{I}^{2}=0 \%\end{array}$

Test for overall effect: $Z=0.74(P=0.46)$

\begin{tabular}{|c|c|c|c|c|c|}
\hline \multicolumn{6}{|l|}{ horse ATG } \\
\hline Champlin, E 2007 & 55 & 68 & 40 & 60 & $35.7 \%$ \\
\hline $\begin{array}{l}\text { Weiden, PL } 1979 \\
\text { Subtotal }(95 \% \mathrm{Cl})\end{array}$ & 8 & $\begin{array}{l}29 \\
97\end{array}$ & 15 & $\begin{array}{l}27 \\
87\end{array}$ & $45.7 \%$ \\
\hline \multicolumn{6}{|c|}{$\begin{array}{l}\text { Heterogeneity: } \mathrm{Tau}^{2}=0.39 ; \mathrm{Chi}^{2}=6.84, \mathrm{df}=1(P=0.009) ; \mathrm{I}^{2}=85 \\
\text { Test for overall effect: } Z=0.42(P=0.67)\end{array}$} \\
\hline Total $(95 \% \mathrm{CI})$ & \multicolumn{3}{|c|}{279} & 256 & $100.0 \%$ \\
\hline \multicolumn{6}{|c|}{$\begin{array}{l}\text { Heterogeneity: } \mathrm{Tau}^{2}=0.03 ; \mathrm{Chi}^{2}=6.41, \mathrm{df}=3(\mathrm{P}=0.09) ; \mathrm{I}^{2}=53 \% \\
\text { Test for overall effect: } \mathrm{Z}=0.37(\mathrm{P}=0.71) \\
\text { Test for subaroun differences: } \mathrm{Chi}^{2}=0.34 . \mathrm{df}=1(\mathrm{P}=0.56) . \mathrm{I}^{2}=0^{2}\end{array}$} \\
\hline $\begin{array}{l}\text { Rabbit ATG } \\
\text { Study or Subgroup }\end{array}$ & $\begin{array}{l}\text { ATC } \\
\text { Events }\end{array}$ & Total & $\begin{array}{l}\text { Contr } \\
\text { Events }\end{array}$ & & I Weight \\
\hline Bacigalupo, A 2001a & 9 & 29 & 5 & 25 & $6.4 \%$ \\
\hline Bacigalupo, A 2001b & 9 & 27 & 11 & 28 & $12.8 \%$ \\
\hline Bacigalupo, A 2010 & 14 & 84 & 24 & 86 & $28.2 \%$ \\
\hline Champlin, E 2007 & 5 & 70 & 7 & 60 & $9.0 \%$ \\
\hline Doney, KC 1981 & 9 & 30 & 12 & 42 & $11.9 \%$ \\
\hline Finke, J 2009 & 12 & 103 & 15 & 98 & $18.3 \%$ \\
\hline Weiden, P.L 1979 & 5 & 29 & 11 & 27 & $13.5 \%$ \\
\hline Total $(95 \% \mathrm{Cl})$ & & 372 & & 366 & $100.0 \%$ \\
\hline Total events & 63 & & 85 & & \\
\hline $\begin{array}{l}\text { Heterogeneity: } \mathrm{Chi}^{2}= \\
\text { Test for overall effect: }\end{array}$ & $\begin{array}{l}8, \mathrm{df}=6 \\
=1.95(\mathrm{~F}\end{array}$ & $\begin{array}{l}6(P=0 \\
P=0.05\end{array}$ & $50) ; 1^{2}=$ & & \\
\hline
\end{tabular}

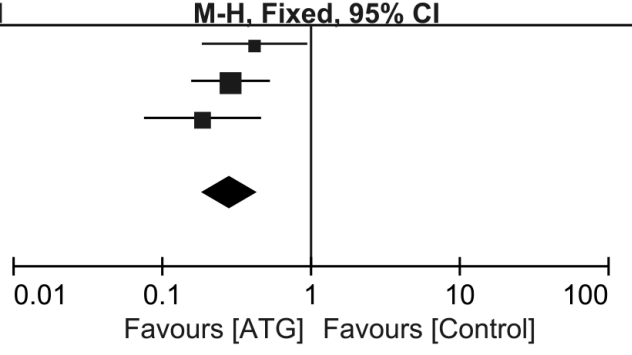

$1.07[0.81,1.41]$

$1.11[0.79,1.57]$

$1.09[0.87,1.35]$

$1.21[0.98,1.50]$

$0.50[0.25,0.98]$

$0.82[0.32,2.06]$

Risk Ratio

M-H. Random, 95\% Cl

$1.05[0.82,1.33]$

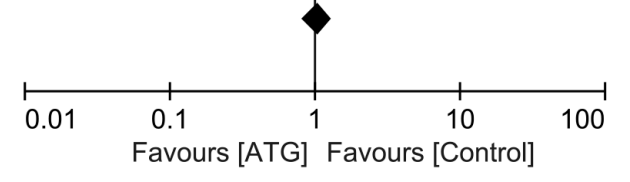

Risk Ratio

Risk Ratio

M-H, Fixed, 95\% Cl

M-H, Fixed, 95\% Cl

$1.55[0.60,4.03]$

$0.85[0.42,1.72]$

$0.60[0.33,1.07]$

$0.61[0.20,1.83]$

$1.05[0.51,2.17]$

$0.76[0.38,1.54]$

$0.42[0.17,1.06]$

$0.75[0.56,1.00]$

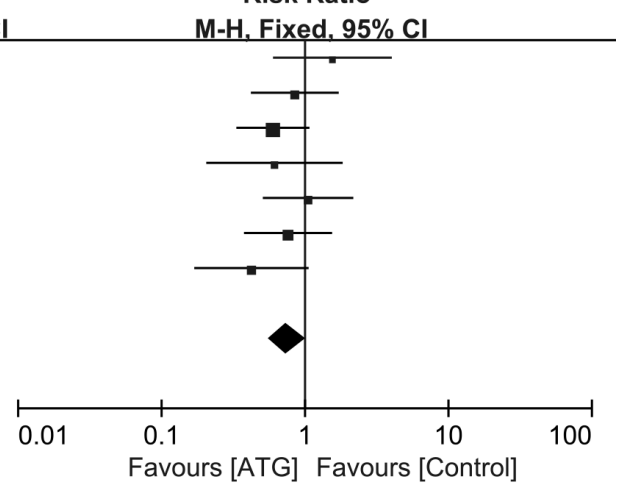




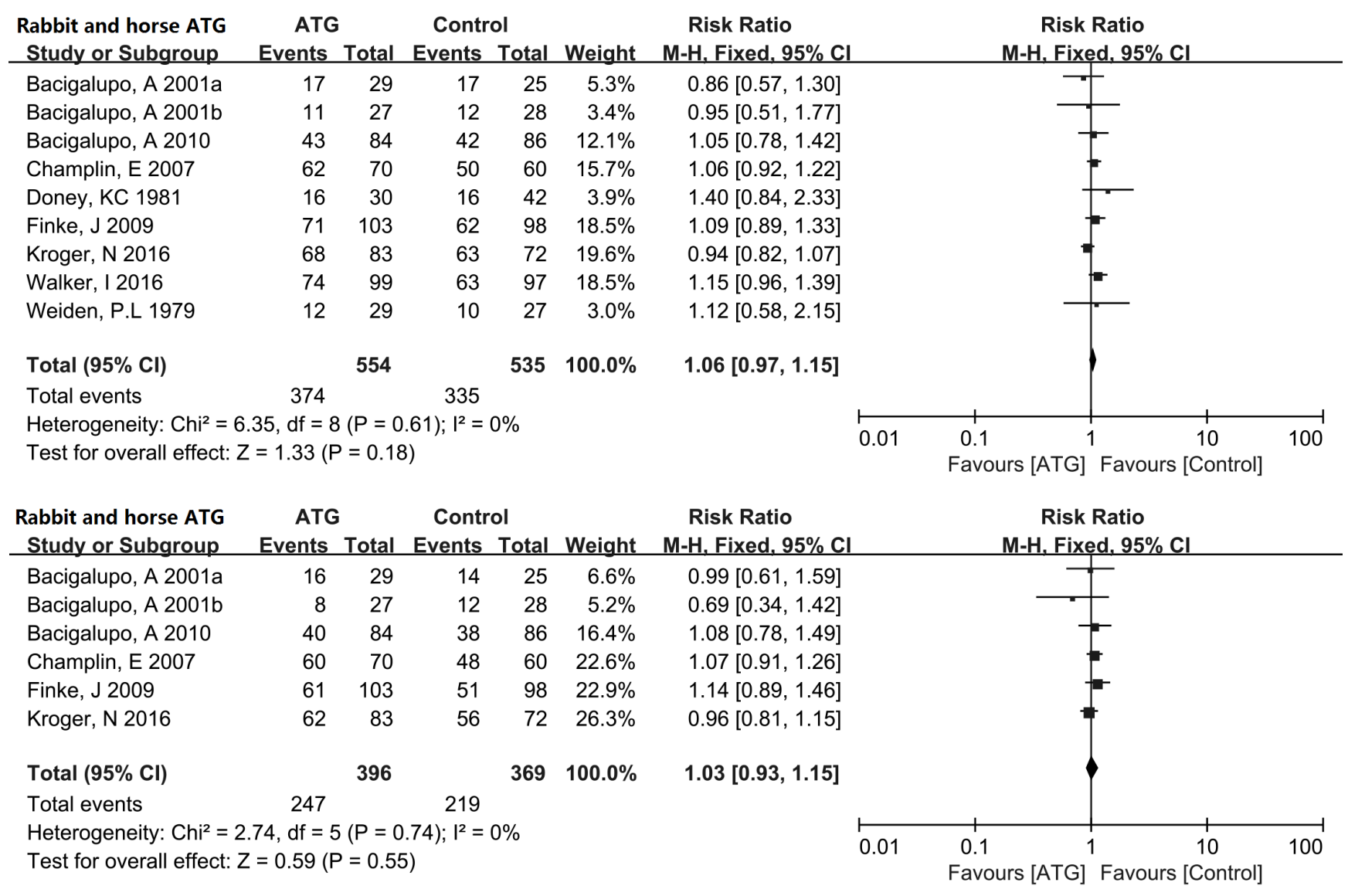

Figure 3: Forest plots analyzing the efficacy of ATG in allo-HCT. (1) Overall aGVHD, (2) aGVHD (grade III-IV), (3) Overall cGVHD, (4) Extensive cGVHD, (5) Relapse, (6) Infections, (7) 100-day TRM, (8) 1-year OS, (9) 2-year OS.

similar in the ATG and non-ATG groups, as was the rate of relapse. Why ATG does not increase the risk of infections and relapse is unknown. One possible explanation is that through opsonization and lysis after complement activation, ATG inhibits reconstitution of the T-cell pool in the peripheral blood, but it does not impair the recovery of B, NK or iNKT cells. This may enable ATG to prevent GVHD without compromising anti-pathogen defenses [54]. Furthermore, ATG may directly eliminate leukemia cells due to its broad-spectrum anti-leukemic activity, as it induces apoptosis and reduces proliferation in both leukemia cell lines and primary human leukemic cells. This is consistent with several in vivo studies [55-59].

Treatment with ATG resulted in a marginal reduction in the rate of 100-day TRM after allo-HCT. This is consistent with prominent aGVHD reduction. We also found that ATG is not associated with a significant benefit for 1-year and 2-year OS. Similar outcomes were reported in other randomized or non-randomized trials, with < 5-year median follow-ups [16, 60, 61]. Nevertheless, the Russell et al. study, with a 6-year median follow-up, showed marginally significant improvement of OS with $4.5 \mathrm{mg} / \mathrm{kg}$ thymoglobulin versus no ATG $(P=0.046)$ [62]. We therefore speculate the OS benefits might become apparent only during longer follow-ups.

We found significant heterogeneity among the included studies evaluating grade III-IV aGVHD and infectious complications. Further sensitivity analysis suggested data extracted from Bacigalupo et al. [30] and Weiden et al. [26] were the primary sources of heterogeneity, respectively. The sample sizes of the two studies in Bacigalupo et al. [30] were smaller $(95 \% \mathrm{CI}=$ $0.58-2.27$ and $0.07-0.69$, respectively) than in the other included studies, and both studies terminated patient accrual before the targeted sample size (64 patients per arm for each study) was reached. In addition, patients in the study from Weiden et al. [26] were given horse ATG as intervention, initially, but patients who developed clinically significant GVHD were randomly assigned to receive rabbit ATG. Accordingly, these were thought to be high-risk factors for introducing bias. Moreover, the included studies have other limitations reflecting differences in the duration of ATG, the graft and donor sources, conditioning regimens and primary diseases. Additional data will be necessary to comprehensively investigate the actions of ATG after allo-HCT before clinical interventions can be individualized. 


\section{MATERIALS AND METHODS}

\section{Inclusion and exclusion criteria}

The studies included in the meta-analysis met the following criteria: i) completed original human prospective RCTs correlating ATG with GVHD after alloHCT in hematological disorders; ii) reported data included demographics, treatment, outcome variables and sufficient information to determine the risk ratios (RRs) and 95\% confidence intervals (CIs); and iii) used any dose, type and duration of ATG, myeloablative or reduced-intensity conditioning regimens, bone marrow or peripheral blood stem cells as graft sources. Exclusion criteria were: i) trials comparing different doses of ATG or different conditioning regimens; ii) retrospective surveillance analyses; and iii) editorials, comments, letters, and abstracts without full text.

\section{Literature search}

A systematic and comprehensive search was performed independently by two authors to collect all the relevant RCTs published through July 2016 in the Medline (PubMed) and Cochrane databases. The following keywords were used to identify the available studies: antithymocyte globulin or ATG, graft-versushost disease or GVHD, and allogeneic hematopoietic cell transplantation or allo-HCT. All the references of relevant articles were further scanned to identify studies that might be eligible for inclusion. Studies were manually selected after reading through abstracts and full texts. Any disagreement was resolved through discussion or consultation with experts in oncology and hematology. No language restrictions were used, which reduced the potential for language bias.

\section{Quality assessment}

To minimize bias and random error, two independent reviewers evaluated the quality of the RCTs by examining the adequacy of the allocation concealment, random sequence generation, blinding of participants and personnel, blinding of outcome assessment, incomplete outcome data, selective reporting and other bias risks. The Cochrane Collaboration tool was used to assess the risk of bias for RCTs with a subjective judgment regarding protection from bias: low risk, high risk or unclear risk of bias, according to the Cochrane Handbook for Systematic Reviews of Interventions Version 5.3.0 (updated March 2011); available from http://handbook.cochrane.org/.

\section{Data extraction and outcomes}

All data regarding baseline characteristics, transplant characteristics, and outcomes were extracted. All the end points we observed were evaluated in univariate analyses. Data extraction was conducted independently by two investigators using standardized extraction of data on the benefits and harms associated with treatment (i.e., ATG versus no ATG). Any discrepancies were resolved by seeking advice from experts in hematology or statistics. The primary outcomes of interest were efficacy as measured by the incidence of aGVHD (overall aGVHD and grade III-IV aGVHD) and cGVHD (overall cGVHD and extensive cGVHD). Secondary outcomes included the incidence of relapse, infections, 100-day TRM and OS at 1 year and 2 years.

\section{Data analysis and statistical methods}

For each trial, binary outcomes were calculated as RRs with $95 \%$ CIs. The power of each study was calculated using the Power and Sample Size Calculation program [22]. Statistical heterogeneity across the studies included in the meta-analysis was assessed using Cochrane's Q statistic and $\chi^{2}$ test with a significance level of $P<0.1$ to select the type of analysis [23]. The fixed-effects model was used for the analysis with an $I^{2}$ $<50 \%$, whereas the random-effects model was used for the analysis with an $I^{2}>50 \%$ [24]. The $I^{2}$ statistic was calculated to quantify possible heterogeneity: $I^{2}$ $>30 \%$ moderate heterogeneity, $I^{2}>75 \%$ considerable heterogeneity. We conducted subgroup analysis or sensitivity analysis to find out sources of heterogeneity when $I^{2}>50 \%$. The Cochrane statistical program Review Manager (Review Manager, Version 5.3) [25] was used for all statistical analyses.

\section{CONFLICTS OF INTEREST}

The authors declare no conflicts of interest.

\section{REFERENCES}

1. Thomas E, Storb R, Clift RA, Fefer A, Johnson FL, Neiman PE, Lerner KG, Glucksberg H, Buckner CD. Bone-marrow transplantation (first of two parts). N Engl J Med. 1975; 292(16): 832-43.

2. Lu DP, Dong L, Wu T, Huang XJ, Zhang MJ, Han W, Chen H, Liu DH, Gao ZY, Chen YH, Xu LP, Zhang YC, Ren HY, et al. Conditioning including antithymocyte globulin followed by unmanipulated HLA-mismatched/ haploidentical blood and marrow transplantation can achieve comparable outcomes with HLA-identical sibling transplantation. Blood. 2006; 107(8): 3065-73. 
3. Chen XH, Gao L, Zhang X, Gao L, Zhang C, Kong PY, Liu H, Peng XG, Sun AH, Qi DG, Gong Y, Wang QY. HLA-haploidentical blood and bone marrow transplantation with anti-thymocyte globulin: long-term comparison with HLA-identical sibling transplantation. Blood Cells Mol Dis. 2009; 43(1): 98-104.

4. Bashey A, Zhang X, Sizemore CA, Manion K, Brown S, Holland HK, Morris LE, Solomon SR. T-cell-replete HLA-haploidentical hematopoietic transplantation for hematologic malignancies using post-transplantation cyclophosphamide results in outcomes equivalent to those of contemporaneous HLA-matched related and unrelated donor transplantation. J Clin Oncol. 2013; 31(10): 1310-6.

5. Raiola AM, Dominietto A, di Grazia C, Lamparelli T, Gualandi F, Ibatici A, Bregante S, Van Lint MT, Varaldo R, Ghiso A, Gobbi M, Carella AM, Signori A, et al. Unmanipulated haploidentical transplants compared with other alternative donors and matched sibling grafts. Biol Blood Marrow Transplant. 2014; 20(10): 1573-9.

6. Di Stasi A, Milton DR, Poon LM, Hamdi A, Rondon G, Chen J, Pingali SR, Konopleva M, Kongtim P, Alousi A, Qazilbash MH, Ahmed S, Bashir Q, et al. Similar transplantation outcomes for acute myeloid leukemia and myelodysplastic syndrome patients with haploidentical versus 10/10 human leukocyte antigen-matched unrelated and related donors. Biol Blood Marrow Transplant. 2014; 20(12): 1975-81.

7. Rocha V, Wagner JE Jr, Sobocinski KA, Klein JP, Zhang MJ, Horowitz MM, Gluckman E. Graft-versus-host disease in children who have received a cord-blood or bone marrow transplant from an HLA-identical sibling. N Engl J Med. 2000; 342(25): 1846-54.

8. Sullivan KM, Agura E, Anasetti C, Appelbaum F, Badger C, Bearman S, Erickson K, Flowers M, Hansen J, Loughran T. Chronic graft-versus-host disease and other late complications of bone marrow transplantation. Semin Hematol. 1991; 28(3): 250-9.

9. Remberger $\mathrm{M}$, Aschan J, Lönnqvist $\mathrm{B}$, Carlens $\mathrm{S}$, Gustafsson B, Hentschke P, Klaesson S, Mattsson J, Ljungman P, Ringdén O. An ethnic role for chronic, but not acute, graft-versus-host disease after HLA-identical sibling stem cell transplantation. Eur J Haematol. 2001; 66(1): 506.

10. Hansen JA, Gooley TA, Martin PJ, Appelbaum F, Chauncey TR, Clift RA, Petersdorf EW, Radich J, Sanders JE, Storb RF, Sullivan KM, Anasetti C. Bone marrow transplants from unrelated donors for patients with chronic myeloid leukemia. N Engl J Med. 1998; 338(14): 962-8.

11. Sierra J, Storer B, Hansen JA, Martin PJ, Petersdorf EW, Woolfrey A, Matthews D, Sanders JE, Storb R, Appelbaum FR, Anasetti C. Unrelated donor marrow transplantation for acute myeloid leukemia: an update of the Seattle experience. Bone Marrow Transplant. 2000; 26(4): $397-$ 404.

12. Kurosawa S, Yamaguchi T, Mori T, Kanamori H, Onishi
Y, Emi N, Fujisawa S, Kohno A, Nakaseko C, Saito B, Kondo T, Hino M, Nawa Y, et al. Patient-reported quality of life after allogeneic hematopoietic cell transplantation or chemotherapy for acute leukemia. Bone Marrow Transplant. 2015; 50(9): 1241-9.

13. Chawla S, Dharmani-Khan P, Liu Y, Prokopishyn N, Amlish Munir M, Griffiths C, Khan FM, Stewart DA, Russell JA, Daly A, Storek J. High serum level of antithymocyte globulin immediately before graft infusion is associated with a low likelihood of chronic, but not acute, graft-versus-host disease. Biol Blood Marrow Transplant. 2014; 20(8): 1156-62.

14. Remberger M, Sundberg B. Rabbit-immunoglobulin $\mathrm{G}$ levels in patients receiving thymoglobulin as part of conditioning before unrelated donor stem cell transplantation. Haematologica. 2005; 90(7): 931-8.

15. Bacigalupo A, Lamparelli $\mathrm{T}$, Bruzzi $\mathrm{P}$, Guidi $\mathrm{S}$, Alessandrino PE, di Bartolomeo P, Oneto R, Bruno B, Barbanti M, Sacchi N, Van Lint MT, Bosi A. Antithymocyte globulin for graft-versus-host disease prophylaxis in transplants from unrelated donors: 2 randomized studies from Gruppo Italiano Trapianti Midollo Osseo (GITMO). Blood. 2001; 98(10): 2942-7.

16. Kröger N, Solano C, Wolschke C, Bandini G, Patriarca F, Pini M, Nagler A, Selleri C, Risitano A, Messina G, Bethge W, Pérez de Oteiza J, Duarte R, et al. Antilymphocyte Globulin for Prevention of Chronic Graft-versus-Host Disease. N Engl J Med. 2016; 374(1): 43-53.

17. Walker I, Panzarella T, Couban S, Couture F, Devins G, Elemary M, Gallagher G, Kerr H, Kuruvilla J, Lee SJ, Moore J, Nevill T, Popradi G, et al. Pretreatment with antithymocyte globulin versus no anti-thymocyte globulin in patients with haematological malignancies undergoing haemopoietic cell transplantation from unrelated donors: a randomised, controlled, open-label, phase 3, multicentre trial. Lancet Oncol. 2016; 17(2): 164-73.

18. Yu ZP, Ding JH, Wu F, Liu J, Wang J, Cheng J, Zhao G. Quality of life of patients after allogeneic hematopoietic stem cell transplantation with antihuman thymocyte globulin. Biol Blood Marrow Transplant. 2012; 18(4): 5939.

19. Theurich S, Fischmann H, Chakupurakal G, ShimabukuroVornhagen A, Chemnitz JM, Holtick U, Rothe A, Scheid C, Hallek M, Skoetz N, von Bergwelt-Baildon M. Antithymocyte globulins for post-transplant graft-versus-host disease prophylaxis-A systematic review and meta-analysis. Crit Rev Oncol Hematol. 2013; 88(1): 178-86.

20. Meijer E, Cornelissen JJ, Löwenberg B, Verdonck LF. Antithymocyteglobulin as prophylaxis of graft failure and graft-versus-host disease in recipients of partially T-celldepleted grafts from matched unrelated donors: a dosefinding study. Exp Hematol. 2003; 31(11): 1026-30.

21. Remberger $M$, Ringdén $O$, Hägglund $H$, Svahn BM, Ljungman P, Uhlin M, Mattsson J. A high antithymocyte globulin dose increases the risk of relapse after reduced 
intensity conditioning HSCT with unrelated donors. Clin Transplant. 2013; 27(4): E368-74.

22. Gibson E, Fenster A, Ward AD. The impact of registration accuracy on imaging validation study design: A novel statistical power calculation. Med Image Anal. 2013; 17(7): 805-15.

23. Coory MD. Comment on: Heterogeneity in meta-analysis should be expected and appropriately quantified. Int $\mathrm{J}$ Epidemiol. 2010; 39(3): 932.

24. DerSimonian R, Laird N. Meta-analysis in clinical trials. Control Clin Trials.1986; 7(3): 177-88.

25. Kawalec P, Mikrut A, Wiśniewska N, Pilc A. The effectiveness of tofacitinib, a novel Janus kinase inhibitor, in the treatment of rheumatoid arthritis: a systematic review and meta-analysis. Clin Rheumatol. 2013; 32(10): 1415-24.

26. Weiden PL, Doney K, Storb R, Thomas ED. Antihuman thymocyte globulin for prophylaxis of graft-versus-host disease. A randomized trial in patients with leukemia treated with HLA-identical sibling marrow grafts. Transplantation. 1979; 27(4): 227-30.

27. Doney KC, Weiden PL, Storb R, Thomas ED. Failure of early administration of antithymocyte globulin to lessen graft-versus-host disease in human allogeneic marrow transplant recipients. Transplantation. 1981; 31(2): 141-3.

28. Champlin RE, Perez WS, Passweg JR, Klein JP, Camitta BM, Gluckman E, Bredeson CN, Eapen M, Horowitz MM. Bone marrow transplantation for severe aplastic anemia: a randomized controlled study of conditioning regimens. Blood. 2007; 109(10): 4582-5.

29. Finke J, Bethge WA, Schmoor C, Ottinger HD, Stelljes M, Zander AR, Volin L, Ruutu T, Heim DA, Schwerdtfeger R, Kolbe K, Mayer J, Maertens JA, et al. Standard graftversus-host disease prophylaxis with or without anti-Tcell globulin in haematopoietic cell transplantation from matched unrelated donors: a randomised, open-label, multicentre phase 3 trial. Lancet Oncol. 2009; 10(9): 85564.

30. Bacigalupo A, Lamparelli T, Milone G, Sormani MP, Ciceri F, Peccatori J, Locasciulli A, Majolino I, Di Bartolomeo P, Mazza F, Sacchi N, Pollicheni S, Pinto V, et al. Pre-emptive treatment of acute GVHD: a randomized multicenter trial of rabbit anti-thymocyte globulin, given on day +7 after alternative donor transplants. Bone Marrow Transplant. 2010; 45(2): 385-91.

31. Shimoni A, Kröger N, Zabelina T, Ayuk F, Hardan I, Yeshurun M, Shem-Tov N, Avigdor A, Ben-Bassat I, Zander AR, Nagler A. Hematopoietic stem-cell transplantation from unrelated donors in elderly patients (age $>55$ years) with hematologic malignancies: older age is no longer a contraindication when using reduced intensity conditioning. Leukemia. 2005; 19(1): 7-12.

32. Laport GG, Sandmaier BM, Storer BE, Scott BL, Stuart MJ, Lange T, Maris MB, Agura ED, Chauncey TR, Wong RM, Forman SJ, Petersen FB, Wade JC, et al. Reduced- intensity conditioning followed by allogeneic hematopoietic cell transplantation for adult patients with myelodysplastic syndrome and myeloproliferative disorders. Biol Blood Marrow Transplant. 2008; 14(2): 246-55.

33. McClune BL, Weisdorf DJ, Pedersen TL, Tunes da Silva G, Tallman MS, Sierra J, Dipersio J, Keating A, Gale RP, George B, Gupta V, Hahn T, Isola L, et al. Effect of age on outcome of reduced-intensity hematopoietic cell transplantation for older patients with acute myeloid leukemia in first complete remission or with myelodysplastic syndrome. J Clin Oncol. 2010; 28(11): 1878-87.

34. Bertz H, Potthoff K, Finke J. Allogeneic stem-cell transplantation from related and unrelated donors in older patients with myeloid leukemia. J Clin Oncol. 2003; 21(8): 1480-4.

35. Stem Cell Trialists' Collaborative Group. Allogeneic peripheral blood stem-cell compared with bone marrow transplantation in the management of hematologic malignancies: an individual patient data meta-analysis of nine randomized trials. J Clin Oncol. 2005; 23(22): 507487.

36. Bacigalupo A, Van Lint MT, Occhini D, Gualandi F, Lamparelli T, Sogno G, Tedone E, Frassoni F, Tong J, Marmont AM. Increased risk of leukemia relapse with highdose cyclosporine A after allogeneic marrow transplantation for acute leukemia. Blood. 1991; 77(7): 1423-8.

37. Storb R, Deeg HJ, Pepe M, Appelbaum F, Anasetti C, Beatty P, Bensinger W, Berenson R, Buckner CD, Clift R. Methotrexate and cyclosporine versus cyclosporine alone for prophylaxis of graft-versus-host disease in patients given HLA-identical marrow grafts for leukemia: long-term follow-up of a controlled trial. Blood. 1989; 73(6): 1729-34.

38. Locatelli F, Zecca M, Rondelli R, Bonetti F, Dini G, Prete A, Messina C, Uderzo C, Ripaldi M, Porta F, Giorgiani G, Giraldi E, Pession A. Graft versus host disease prophylaxis with low-dose cyclosporine-A reduces the risk of relapse in children with acute leukemia given HLA-identical sibling bone marrow transplantation: results of a randomized trial. Blood. 2000; 95(5): 1572-9.

39. Wagner JE, Thompson JS, Carter SL, Kernan NA. Effect of graft-versus-host disease prophylaxis on 3-year diseasefree survival in recipients of unrelated donor bone marrow (T-cell Depletion Trial): a multi-centre, randomised phase II-III trial. Lancet. 2005; 366(9487): 733-41.

40. Marmont AM, Horowitz MM, Gale RP, Sobocinski K, Ash RC, van Bekkum DW, Champlin RE, Dicke KA, Goldman JM, Good RA. T-cell depletion of HLA-identical transplants in leukemia. Blood. 1991; 78(8): 2120-30.

41. Haidinger M, Geyeregger R, Poglitsch M, Weichhart T, Zeyda M, Vodenik B, Stulnig TM, Böhmig GA, Hörl WH, Säemann MD. Antithymocyte globulin impairs T-cell/antigen-presenting cell interaction: disruption of immunological synapse and conjugate formation. Transplantation. 2007; 84(1): 117-21. 
42. Shimony O, Nagler A, Gellman YN, Refaeli E, Rosenblum N, Eshkar-Sebban L, Yerushalmi R, Shimoni A, Lytton SD, Stanevsky A, Or R, Naor D. Anti-T lymphocyte globulin (ATG) induces generation of regulatory $\mathrm{T}$ cells, at least part of them express activated CD44. J Clin Immunol. 2012; 32(1): 173-88.

43. LaCorcia G, Swistak M, Lawendowski C, Duan S, Weeden T, Nahill S, Williams JM, Dzuris JL. Polyclonal rabbit antithymocyte globulin exhibits consistent immunosuppressive capabilities beyond cell depletion. Transplantation. 2009; 87(7): 966-74.

44. Kalwak K, Mosoń I, Cwian J, Gorczyńska E, Toporski J, Turkiewicz D, Latos-Grazyńska E, Chybicka A. A prospective analysis of immune recovery in children following allogeneic transplantation of t-cell-depleted or non-T-cell-depleted hematopoietic cells from HLAdisparate family donors. Transplant Proc. 2003; 35(4): 1551-5.

45. Meijer E, Bloem AC, Dekker AW, Verdonck LF. Effect of antithymocyte globulin on quantitative immune recovery and graft-versus-host disease after partially T-cell-depleted bone marrow transplantation: a comparison between recipients of matched related and matched unrelated donor grafts. Transplantation. 2003; 75(11): 1910-3.

46. Fehse N, Fehse B, Kröger N, Zabelina T, Freiberger P, Krüger W, Kabisch H, Erttmann R, Zander AR. Influence of anti-thymocyte globulin as part of the conditioning regimen on immune reconstitution following matched related bone marrow transplantation. J Hematother Stem Cell Res. 2003; 12(2): 237-42.

47. Soiffer RJ, Lerademacher J, Ho V, Kan F, Artz A, Champlin RE, Devine S, Isola L, Lazarus HM, Marks DI, Porter DL, Waller EK, Horowitz MM, et al. Impact of immune modulation with anti-T-cell antibodies on the outcome of reduced-intensity allogeneic hematopoietic stem cell transplantation for hematologic malignancies. Blood. 2011; 117(25): 6963-70.

48. Baron F, Labopin M, Blaise D, Lopez-Corral L, Vigouroux S, Craddock C, Attal M, Jindra P, Goker H, Socié G, Chevallier P, Browne P, Sandstedt A, et al. Impact of in vivo T-cell depletion on outcome of AML patients in first CR given peripheral blood stem cells and reduced-intensity conditioning allo-SCT from a HLA-identical sibling donor: a report from the Acute Leukemia Working Party of the European Group for Blood and Marrow Transplantation. Bone Marrow Transplant. 2014; 49(3): 389-96.

49. Crocchiolo R, Esterni B, Castagna L, Fürst S, ElCheikh J, Devillier R, Granata A, Oudin C, Calmels B, Chabannon C, Bouabdallah R, Vey N, Blaise D. Two days of antithymocyte globulin are associated with a reduced incidence of acute and chronic graft-versus-host disease in reduced-intensity conditioning transplantation for hematologic diseases. Cancer. 2013; 119(5): 986-92.

50. Wolschke C, Zabelina T, Ayuk F, Alchalby H, Berger J, Klyuchnikov E, Pein UM, Schumacher S, Amtsfeld
G, Adjallé R, Wortmann F, Lellek H, Randenborgh A, et al. Effective prevention of GVHD using in vivo T-cell depletion with anti-lymphocyte globulin in HLAidentical or -mismatched sibling peripheral blood stem cell transplantation. Bone Marrow Transplant. 2014; 49(1): 12630.

51. Wang Y, Fu HX, Liu DH, Xu LP, Zhang XH, Chang YJ, Chen YH, Wang FR, Sun YQ, Tang FF, Liu KY, Huang XJ. Influence of two different doses of antithymocyte globulin in patients with standard-risk disease following haploidentical transplantation: a randomized trial. Bone Marrow Transplant. 2014; 49(3): 426-33.

52. Remberger M, Svahn BM, Mattsson J, Ringdén O. Dose study of thymoglobulin during conditioning for unrelated donor allogeneic stem-cell transplantation. Transplantation. 2004; 78(1): 122-7.

53. Hamadani M, Blum W, Phillips G, Elder P, Andritsos L, Hofmeister C, O’Donnell L, Klisovic R, Penza S, Garzon R, Krugh D, Lin T, Bechtel T, et al. Improved nonrelapse mortality and infection rate with lower dose of antithymocyte globulin in patients undergoing reducedintensity conditioning allogeneic transplantation for hematologic malignancies. Biol Blood Marrow Transplant. 2009; 15(11): 1422-30.

54. Servais S, Menten-Dedoyart C, Beguin Y, Seidel L, Gothot A, Daulne C, Willems E, Delens L, Humblet-Baron S, Hannon M, Baron F. Impact of Pre-Transplant Anti-T Cell Globulin (ATG) on Immune Recovery after Myeloablative Allogeneic Peripheral Blood Stem Cell Transplantation. PLoS One. 2015; 10(6): e0130026.

55. Liu H, Qin Y, Wang X, Xie K, Yang Y, Zhu J, Zhao C, Wang C. Polyclonal rabbit antithymocyte globulin induces apoptosis and has cytotoxic effects on human leukemic cells. Clin Lymphoma Myeloma Leuk. 2012; 12(5): 345-54.

56. Ayuk F, Maywald N, Hannemann S, Larsen U, Zander A, Kröger N. Comparison of the cytotoxicity of 4 preparations of anti-T-cell globulins in various hematological malignancies. Anticancer Res. 2009; 29(4): 1355-60.

57. Ayuk FA, Atassi N, Schuch G, Mina S, Fang L, Bokemeyer C, Fehse B, Zander AR, Kröger N. Complement-dependent and complement-independent cytotoxicity of polyclonal antithymocyte globulins in chronic lymphocytic leukemia. Leuk Res. 2008; 32(8): 1200-6.

58. Grüllich C, Ziegler C, Finke J. Rabbit anti T-lymphocyte globulin induces apoptosis in peripheral blood mononuclear cell compartments and leukemia cells, while hematopoetic stem cells are apoptosis resistant. Biol Blood Marrow Transplant. 2009; 15(2): 173-82.

59. Yoshimi A, Ito M, Kojima S. Leukemic cell death induced by antithymocyte globulin. Leuk Res. 2005; 29(7): 821-7.

60. Socié G, Schmoor C, Bethge WA, Ottinger HD, Stelljes M, Zander AR, Volin L, Ruutu T, Heim DA, Schwerdtfeger R, Kolbe K, Mayer J, Maertens JA, et al. Chronic graft-versushost disease: long-term results from a randomized trial on graft-versus-host disease prophylaxis with or without anti- 
T-cell globulin ATG-Fresenius. Blood. 2011; 117(23): 6375-82.

61. Mohty M, Labopin M, Balère ML, Socié G, Milpied N, Tabrizi R, Ifrah N, Hicheri Y, Dhedin N, Michallet M, Buzyn A, Cahn JY, Bourhis JH, et al. Antithymocyte globulins and chronic graft-vs-host disease after myeloablative allogeneic stem cell transplantation from HLA-matched unrelated donors: a report from the Sociéte Française de Greffe de Moelle et de Thérapie Cellulaire. Leukemia. 2010; 24(11): 1867-74.
62. Russell JA, Turner AR, Larratt L, Chaudhry A, Morris D, Brown C, Quinlan D, Stewart D. Adult recipients of matched related donor blood cell transplants given myeloablative regimens including pretransplant antithymocyte globulin have lower mortality related to graft-versus-host disease: a matched pair analysis. Biol Blood Marrow Transplant. 2007; 13(3): 299-306. 